\title{
Improvement of Luminescence Quantum Efficiency by Intermolecular Interaction
}

\author{
Hwasoon Jung, Kyungwook Kim. Subin Lee, Hyesu Hwang, Kwangseo Park, \\ Jinho Kim, Soon-Ki Kwon," and Youngjin Kang ${ }^{*}$
}

\author{
Division of Science Education \& Department of Chemistry, Kangwon National University, Chtmcheon 200-701, Korea \\ "E-mail: kangv@kangwon.ackr. \\ "School of Nano \& Advanced Materials Science and Engeering and ERI, Gyeongsang National University, Jinju 660-701, Korea \\ Received July 11,2007
}

Key Words : Fluorescence, Quantum yields, Photoluminescent property, Crystal structure, Intermolecular interaction

Due to their unique photophysical properties, highly fluorescent compounds are currently of great interest for material science applications, such as photo-electronics, organic light-emitting diodes (OLEDs) and chemical sensors. ${ }^{\prime}$ In particular, efforts have focused on the improvement of fluorescence quantum yields $\left(\Phi_{\mathrm{T}}\right)$, since the $\Phi_{\mathrm{T}}$ of emitting materials and the device efficiency in OLEDs are generally related. ${ }^{2}$ For this purpose, several approaches have been suggested including the attachment of anthracene and/or pyrene units having high $\Phi_{T}$ to the molecular framework, the extension of $\pi$-conjugation and the introduction of electronwithdrawing groups ( $\mathrm{F}, \mathrm{CN}$, etc) as substituents. ${ }^{3}$ Among such approaches, the introduction of electron-withdrawing groups to the molecular backbone has received greater attention, because the molecules containing these groups have shown unusual and high fluorescence quantum efficiency through the intermolecular interactions. Such phenomenon is often called aggregation induced emission (AIE). ${ }^{+}$ During our ongoing efforts on the development of luminescent materials, we have observed that fluorene- and anthracene-based compounds linked by a perfluorocyclopentene core unit have high fluorescence quantum efficiency as compared to 9,10-diphenylanthracene (DPA). ${ }^{5}$ Our interest in the synthesis of highly fluorescent materials containing a perfluorocyclopentene core unit, which can provide binding sites for hydrogen atoms of adjacent molecules via intermolecular interactions, has prompted us to investigate the syntheses and photophysical properties of their derivatives. Here, we report on the syntheses, crystal structure and optical properties of a series of V-shaped molecules containing the linker of an electron-withdrawing moiety. In addition, the effect of electron-withdrawing substituents on fluorescence quantum efficiency has been systematically evaluated at the molecular level.

Scheme I outlines the synthesis of the series of benzothiophene derivatives. Compound $\mathbf{1}$ and $\mathbf{2}$ were prepared by the addition of octafluorocyclopentene to the corresponding lithiated compound, prepared from the reaction of a small excess of $n-\mathrm{BuLi}$ and the bromoarene at $-78{ }^{\circ} \mathrm{C}$. The standard work up and crystallization from $\mathrm{CH}_{2} \mathrm{Cl}_{2} /$ hexane produces compounds as colorless or pale yellow solids in moderate yjelds (45-55\%). In addition, to evaluate the effect of a perfluorocyclopentene ring on structural features and photoluminescence, we have synthesized an aromatic analogue of compound 3, through Pd-mediated Suzuki coupling. The structures of 1-3 have been characterized by ${ }^{1} \mathrm{H}-\mathrm{NMR},{ }^{13} \mathrm{C}-\mathrm{NMR}$ and elemental analyses, including $\mathrm{X}$ ray diffraction analysis of 2 .

Yellow crystals of $\mathbf{2}$ that were suitable for $\mathrm{X}$-ray analysis were obtained by the slow evaporation in $\mathrm{CH}_{2} \mathrm{Cl}_{2}$ and hexane. The crystal structures and selected bond lengths and angles of $\mathbf{1}$ are presented in Figure 1. As shown in the Figure, two benzothiophene groups connected by the hexafluorocyclopentene linker are twisted with respect to each other. Note that the hexafluorocyclopentene linker and one ( $\mathrm{S} 1 \mathrm{ring}$ ) of two benzothiophene rings are arranged a nearly coplanar manner with a dihedral angle of $5.44^{\circ}$, while the other (S2 ring) is highly tilted toward the hexafluorocyclopentene core with a dihedral angle of $71.96^{\circ}$. This observation is very uncommon in diarylethene derivatives
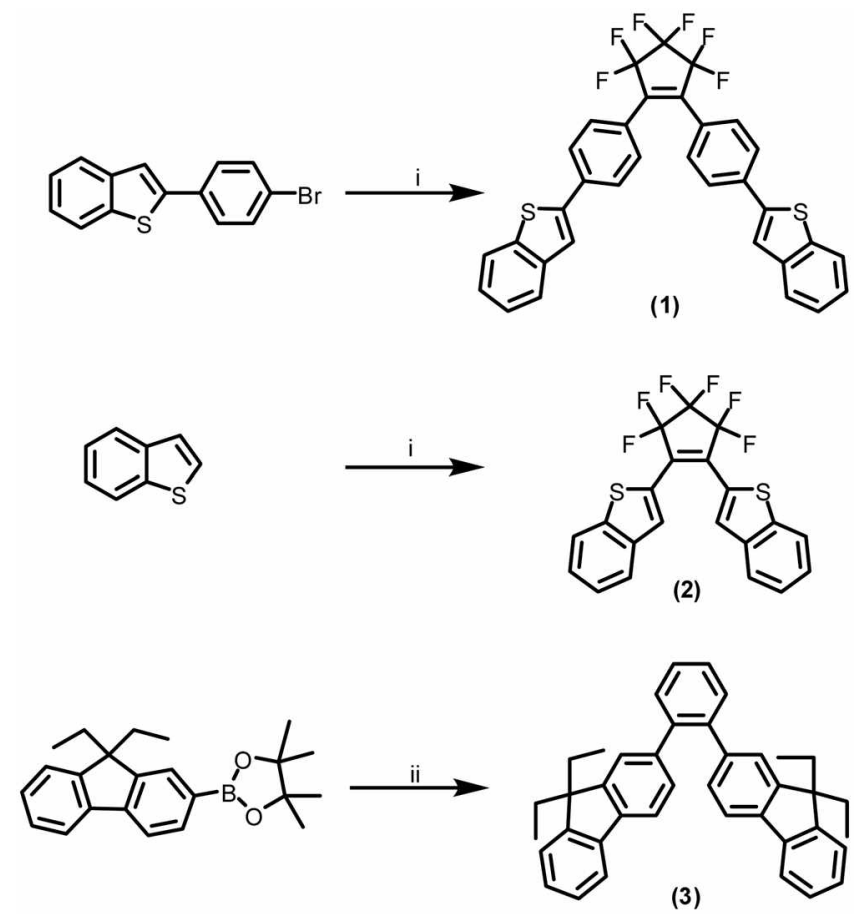

Scheme 1. Synthetic routes of 1,2 and 3. (i) $n-B u L i / T H F, ~-78^{\circ} \mathrm{C}$, octafluorocyclopentene $\left(0.5\right.$ eq); (ii) $\mathrm{K}_{2} \mathrm{CO}_{3}$, benzyltrimethylammoniumchloride, $\mathrm{Pd}\left(\mathrm{PJPh}_{3}\right)_{4}(5 \mathrm{~mol} \%)$, toluene, reflux. 

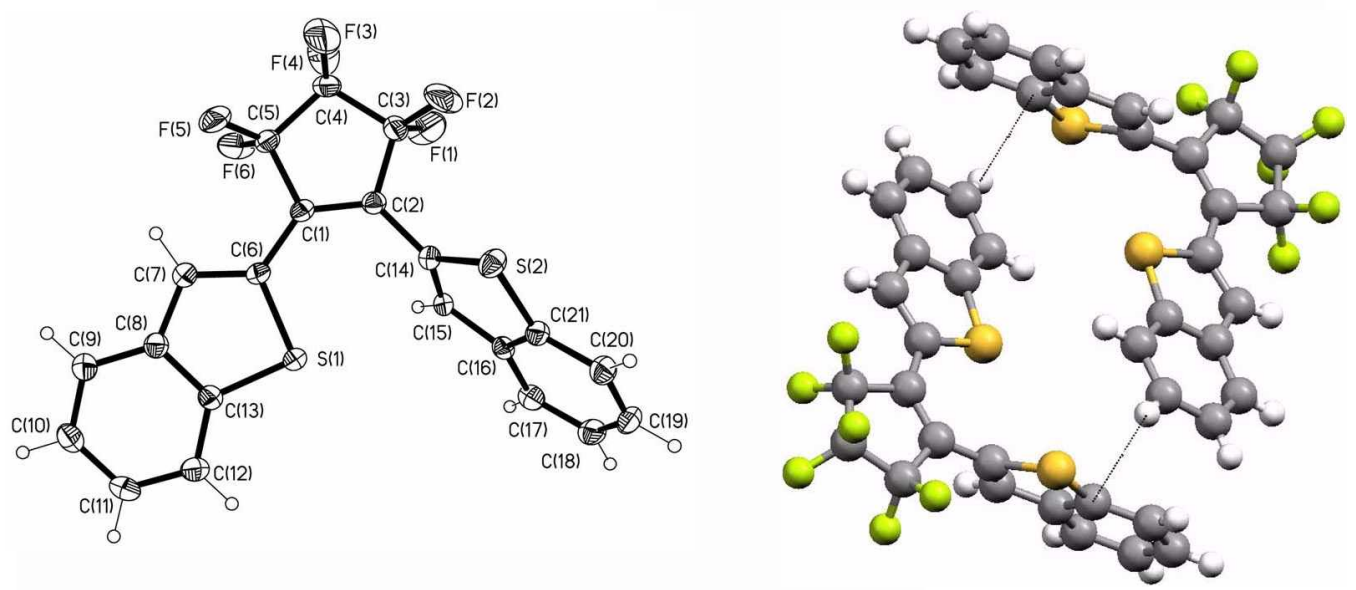

Figure 1. Molccular structure of 2 with $50 \%$ thermal ellipsoids and a labeling scheme (left); Diagram of two adjacent molccules in a unit cell packing showing inacrocyclic structure through intermolecular $\mathrm{C} / \pi) \cdots \mathrm{H}$ interactions (right). Selected bond lengths $(\Lambda)$ and angles (deg): C1-C6 1.450(3), C2-C14 1.474(2), C1-C2-C14 128.77(17), C2-C1-C6 130.70(17).

and also indicates the lack of effective $\pi$-conjugation throughout the whole molecule. This unusual arrangement of two benzothiophene rings around the perfluorocyclopentene core can be due to the intermolecular interactions between two adjacent asymmetric units (See supporting information). There is an interesting spatial arrangement in the crystal lattice. Compound 2 exhibits face-to-edge $\mathrm{C}(\pi)$ $\cdots \mathrm{H}$ interactions, as demonstrated by the distance of $\mathrm{C} 21$ H11 $(2.880 \AA)$. As a consequence, 2 shows macrocyclic structure that has an approximately $\mathrm{C} 2$ symmetry. The separation distance between two mean planes (C14-C16, $\mathrm{C} 21$ and S2) is approximately $10.42 \AA$.

The bond lengths $\mathrm{Cl}-\mathrm{C} 6$ and $\mathrm{C} 2-\mathrm{C} 14$ are $1.450(3) \AA$ and $1.474(2) \AA$, respectively. These are similar to those of previously reported diarylethene compounds. ${ }^{5}$ Compound 2 has several intermolecular interactions that appear to direct the expanded packing of the solid-state structure. The packing diagram (See supporting information) displays a zigzag shape of molecules with slipped $\mathrm{H} \cdots \mathrm{F}$ and $\mathrm{C}(\pi) \cdots \mathrm{H}$ intermolecular interactions ( $\mathrm{F} 6 \cdots \mathrm{H} 9,2.49 \AA ; \mathrm{C} 16 \cdots \mathrm{H} 7$, $2.85 \AA ; \mathrm{Cl} 7 \cdots \mathrm{H} 7,2.89 \AA)$. However, additional intermolecular interactions, such as $\pi-\pi$ stacking, were not found in the packing structure of 2 .

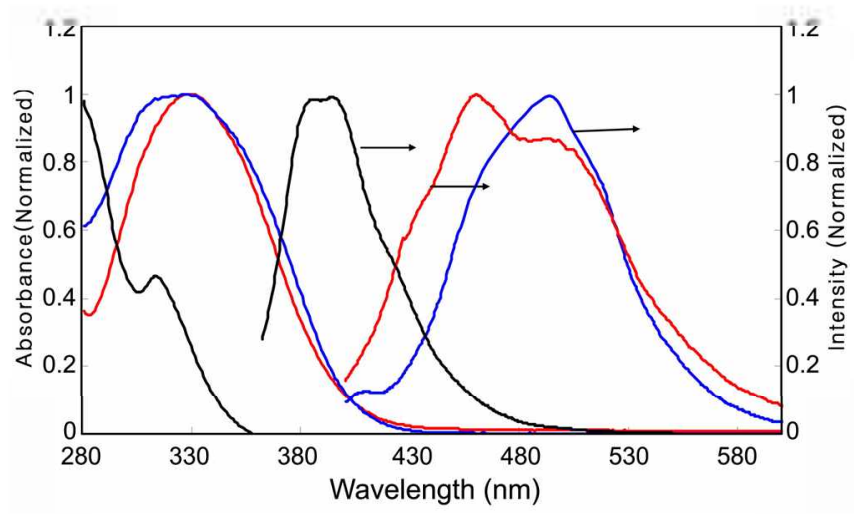

Figure 2. $\Lambda$ bsorption and emission spectra of 1 (red line), 2 (blue line) and 3 (black line).
UV/Vis absorption spectra of $\mathbf{1}$, and $\mathbf{2}$ exhibit intense absorption bands between $280 \mathrm{~nm}$ and $400 \mathrm{~nm}$, indicating that the electronic transitions are mostly benzothiophenecentered $\pi-\pi$. The optical band gaps of 1 and 2 were determined by their corresponding absorption threshold ( $2.86 \mathrm{eV}$ for $1,2.91 \mathrm{eV}$ for 2 , respectively). To examine the effect of the perfluorocyclopentene linkage on the electronic transition, we measured the absorption spectrum of $\mathbf{3}$, which contains a benzene ring instead of perfluorocyclopentene, under the same conditions. Interestingly, the maximum peak observed for 3 exhibits a significant blue shift $\left(\lambda_{\max }=280\right.$ $\mathrm{nm}$ ) relative to those of 1 , and 2 . In addition, the UV edge in $\mathbf{3}$ appears at a much higher energy than those in $\mathbf{1}$ and $\mathbf{2}$. From the point of those observations, when perfluorocyclopentene unit is employed as a core, more effective $\pi$ conjugation occurs between the core and side units. However, when the core unit of perfluorocyclopentene is replaced by benzene, effective $\pi$-conjugation throughout whole molecules does not occur. This might be due to the strong steric repulsion between the benzene core and the bulky 9,9-diethylfluorene. The emission spectra of compounds 1,2 and 5 in solution at room temperature are dominated by fluorescence in the region of $380-550 \mathrm{~nm}$. The $\lambda_{\max }$ values in emission spectra are at $504 \mathrm{~nm}$ for $1,463 \mathrm{~nm}$ (495(sh)) for 2 and $396 \mathrm{~nm}$ for 3 , respectively. This result can also be explained by correlating the electronic and structural effects originating from the perfluorocyclopentene unit. The introduction of perfluorocyclopentene gives rise to an increase in the electron-withdrawing nature of molecules and effective $\pi$-conjugation between core and side units, leading to more red-shifts of $\mathbf{1}$ and 2 than in 3 . It is worth noting that the quantum yields of $\mathbf{1}$ is higher than that of 9,10-diphenylanthracene, which is a highly fluorescent molecule $\left(\Phi_{\mathrm{T}}=0.95\right)$ and often used as the blue standard in quantum yield measurement. ${ }^{6}$ To investigate the effect of the core unit on the fluorescence quantum yield, we have synthesized two compounds, 1,2-bis(9,9-diethylfluoren-2yl)-3,3,4,4,5,5-hexafluorocyclopentene (BFFC) and 1,2- 


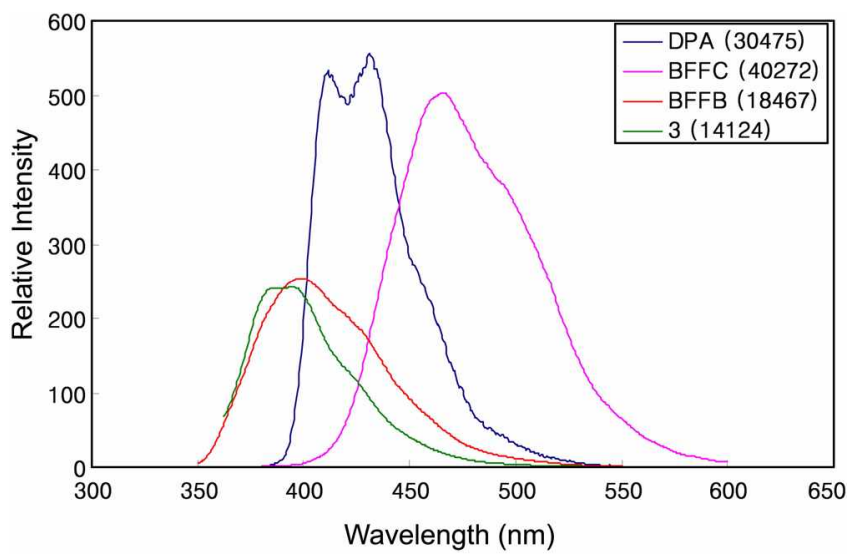

Figure 3. Comparison of fluorescence intensity for DPA, BFFC, BFFB and 3. insect: integrated fluorescence intensity (excitation at $340 \mathrm{~nm}$, slit width $3 \mathrm{~nm}$ ).

difluoro-4,5-bis(9,9'-diethylfluoren-2-yl)benzene (DFFB) according to previous literature. The deternination of the quantum yield was performed by the comparative method, which was established by Williams et al. ${ }^{7}$ As shown in Figure 3 , the integrated fluorescence intensity has the following order: BFFC $>$ DPA $>$ DFFB $>3$. Compound 3, which is linked by a benzene ring and lacks a fluorine atom, shows the lowest quantum yield. The striking difference between BFFC, DFFB and 3 is the number of fluorine atoms in core unit. In general, the rigidity of molecular structure has an influence on the fluorescence quantum yields. ${ }^{\gamma}$ As reported previously, BFFC has a 2-D puckered sheet structure through a lot of intermolecular $\mathrm{C}(\pi) \cdots \mathrm{H}$, $\mathrm{C}(\pi) \cdots \mathrm{F}$ and $\mathrm{F} \cdots \mathrm{H}$ in the crystal packing. However, BFFB has a 1-D column-like structure in the crystal packing. ${ }^{3}$ The structural difference is clearly caused by the number of fluorine atoms (intermolecular interactions). Despite the lack of crystal structure for $\mathbf{3}$, we believe that strong intermolecular interactions render molecules with rigidity and lead to high quantum efficiency.

In summary, highly fluorescent compounds containing a perfluorocyclopentene core have been synthesized and the effect on fluorescence quantum efficiency of their derivatives has been systematically evaluated. The fluorescence quantum efficiency depends on the number of fluorine atoms. As internolecular interactions increase, molecules become rigid, leading to higher fluorescence quantum efficiency.

\section{Experimental Section}

General Methods. All experiments were performed under dry $\mathrm{N}_{2}$ atmospheres using standard Schlenk techniques. All solvents were freshly distilled over appropriate drying reagents prior to use. The starting materials 2 -bromo- 9,9 diethylfluorene, 2-bromo-9,9'-dihexylfluorene, and 2-bromo$9,9^{\prime}$-spirobifluorene were prepared according to literature procedures. ${ }^{9}$ For general experimental details, see supporting information.
Synthesis of 1,2-Bis\{4-(2-benzo[b]thiophenyl)phenyl\}3,3,4,4,5,5-hexafluorocyc lopentene (1). Yields: $45 \%$; m.p. $249-250^{\circ} \mathrm{C}$. MS (EI): $\mathrm{m} / \mathrm{z}=592[\mathrm{M}]^{+}$. 'H-NMR $\left(\mathrm{CDCl}_{3}\right.$, $400 \mathrm{MHz}) \delta: 7.84(\mathrm{~d}, J=1.5 \mathrm{~Hz}, 1 \mathrm{H}), 7.75(\mathrm{~d}, J=1.6 \mathrm{~Hz}$, $1 \mathrm{H}), 7.72(\mathrm{AB}, J=8.4 \mathrm{~Hz}, 2 \mathrm{H}), 7.60(\mathrm{~s}, 1 \mathrm{H}), 7.46(\mathrm{AB}, J=9$ $\mathrm{Hz}, 2 \mathrm{H}), 7.35(\mathrm{~m}, 2 \mathrm{H}) .{ }^{13} \mathrm{C}-\mathrm{NMR}\left(\mathrm{CDCl}_{3}, 100 \mathrm{MHz}\right) \delta$ : $142.9,140.8,140.1,136.7,130.3,127.7,127.2,125.3,125.1$ 124.3, 122.7, 121.1, 30.1. Anal. Calcd for $\mathrm{C}_{33} \mathrm{H}_{18} \mathrm{~F}_{6} \mathrm{~S}_{2}: \mathrm{C}$, $66.88 ; \mathrm{H}, 3.06$. Found: $\mathrm{C}, 66.79 ; \mathrm{H}, 2.98$.

Synthesis of 1,2-Bis(2-benzo[b] thiophenyl)-3,3,4,4,5,5hexafluorocyclope ntene (2). ${ }^{10}$ Yields: 51\%; m.p. 132-134 ${ }^{\circ} \mathrm{C}$. MS (EI): $\mathrm{m} / \mathrm{z}=440[\mathrm{M}]^{+} .{ }^{1} \mathrm{H}-\mathrm{NMR}\left(\mathrm{CDCl}_{3}, 400 \mathrm{MHz}\right)$ $\delta: 7.86-7.83(\mathrm{~m}, 2 \mathrm{H}), 7.76-8.11(\mathrm{~m}, 4 \mathrm{H}), 7.38-7.43(\mathrm{~m}, 4 \mathrm{H})$. ${ }^{13} \mathrm{C}-\mathrm{NMR}\left(\mathrm{CDCl}_{3}, 100 \mathrm{MHz}\right) \delta: 130.7,130.0,129.6,128.95$, 128.4, 126.1, 125.2. Anal. Calcd for $\mathrm{C}_{21} \mathrm{H}_{10} \mathrm{~F}_{6} \mathrm{~S}_{2}: \mathrm{C}, 57.27$; $\mathrm{H}, 2.29$. Found: $\mathrm{C}, 57.10 ; \mathrm{H}, 2.31$.

Synthesis of 1,2-Bis(9,9-diethylfluoren-2-yl)benzene (3). Yields: $55 \% \mathrm{MS}(\mathrm{EI}): \mathrm{m} / \mathrm{z}=518\left[\mathrm{M}^{+}\right] .{ }^{1} \mathrm{H}-\mathrm{NMR}\left(\mathrm{CDCl}_{3}\right.$, $400 \mathrm{MHz}) \delta: 7.16-7.71(18 \mathrm{H}, \mathrm{m}), 1.95(8 \mathrm{H}, \mathrm{q}), 0.29(12 \mathrm{H}, \mathrm{t}$, $J=7.23 \mathrm{~Hz}$ ). Anal. Caled for $\mathrm{C}_{40} \mathrm{H}_{38}: \mathrm{C}, 92.62 ; \mathrm{H}, 7.38$. Found: $\mathrm{C}, 96.55 ; \mathrm{H}, 7.29$.

Fluorescence Measurement. UV/Vis and photoluminescent spectra were obtained with UV/Vis spectrometer Lambda 900 and a Perkin Elmer Luminescence spectrometer LS 50B, respectively. All solutions for photophysical experiments were degassed with more than three repeated freeze-pump-thaw cycles in a vacuum line. The emission slit width was at $3-5 \mathrm{~nm}$. The relative quantum yields of $\mathrm{PL}$ $\left(\Phi_{\mathrm{PL}}\right)$ for all compounds were determined relative to $9,10-$ diphenylanthracene $\left(\Phi_{\mathrm{PL}}=0.95\right)$ as the standard. A range of concentrations of solution of all compounds and standard were measured such that absorbance were less than 0.10 at the excitation wavelength $\left(\lambda_{\mathrm{ex}}=340 \mathrm{~nm}\right)$. The quantum yield was then measured by the previously known process. ${ }^{\text {? }}$

X-ray Crystallography. All data were collected on a Bruker SMART diffractometer equipped with a graphite monochromated Mo $\mathrm{K} \alpha(\lambda=0.71073 \AA)$ radiation, and a CCD detector; 50 frames of two-dimensional diffraction images were collected and processed to obtain the cell parameters and orientation matrix. All data collections were performed at $173 \mathrm{~K}$. Decay was monitored by 50 standard data frames measured at the beginning and end of data collection. The program SAINTPLUS ${ }^{11}$ was used for integration of the diffraction profiles. The structures were solved by direct methods using the SHELXS program of the SHELXTL package ${ }^{12}$ and refined by full matrix least squares against $F^{2}$ for all data using SHELXI. All non-H atoms were refined with anisotropic displacement parameters. Hydrogen atoms were placed in idealized positions $\left[U_{\text {ise }}=1.2 U_{\text {eq }}\right.$ (parent atom) $]$ and refined using a riding model with the exception of the hydrogen atoms of the coordinated water molecule. The initial positions of the hydrogen atoms of water molecule were obtained from difference electron density maps. Their positional parameters were then refined using a riding model. The summary of the crystal data, experimental details and refinement results for 2 is listed in Table 1. Crystallographic data for the structure 
Table 1. Crystallographic data and strueture refinement for 2

\begin{tabular}{ll}
\hline Chemical formula & $\mathrm{C}_{21} \mathrm{H}_{10} \mathrm{~F}_{6} \mathrm{~S}_{2}$ \\
Formula weight & 440.41 \\
$T(\mathrm{~K})$ & $173(2)$ \\
Crystal system & Monoclinic \\
Space group & $P 2(1) / \mathrm{c}$ \\
$a(\AA)$ & $12.6272(6)$ \\
$b(\AA)$ & $6.0836(3)$ \\
$c(\AA)$ & $23.9412(12)$ \\
$\beta\left({ }^{0}\right)$ & $103.6890(10)$ \\
$V\left(\AA^{3}\right)$ & $1786.89(15)$ \\
$Z$ & 4 \\
Absorption coefficient $\left(\mathrm{mm}^{-1}\right)$ & 0.363 \\
$F(000)$ & 888 \\
Crystal size (mm $\left.{ }^{3}\right)$ & $0.80 \times 0.80 \times 0.30$ \\
$\theta$ range ( $\left.^{0}\right)$ & 1.66 to 28.30 \\
Reflections collected / Unique & $10613 / 4145$ \\
Data / restraints / parameters & $4145 / 0 / 262$ \\
Goodness-of-fit on $F^{2}$ & 1.069 \\
Final $R$ indices & $R_{1}=0.0446,4 R_{2}=0.1137$ \\
\hline
\end{tabular}

reported here have been deposited at the Cambridge Crystallographic Data Center, CCDC No. 653537. Copies of the data can be obtained free of charge on application to CCDC, 12 Union Road, Cambridge CB2 1EZ, UK; fax: +44 1223336 033; e-mail: deposit(accdc.cam.ac.uk), or electronically via www.ccde.cam.ac.uk/data_request/cif.

Supporting Information. General syntheses, crystal data, bond lengths, bond angles and packing diagram are available on the request from the corresponding author. (Fax: +82-33242-9598, E-mail: kangy(a)kangwon.ac.kr)

Acknowledgement. This research was supported by a grant (F0004021) from Information Display R\&D Center, one of the 21st Century Frontier R\&D Program funded by the Ministry of Commerce, Industry and Energy of Korean government. This work was partially supported by KOSEF $\mathrm{R} \& \mathrm{E}(2006)$.

\section{References}

I. (a) Wei, Y.; Chen, C.-T. J. Am. Chem. Soc. 2007, 129, 7478. (b) Balan, B.; Gopidas, K. R. Chemt. Evr. J. 2007, J3, 5173. (c) Hauser, P. C.; Liang, C. L. C.; Mueller, B. Meas. Sci. Technol. 1995, 6, 1081. (d) Kang, Y.; Moon, S.-T.; Park, S.; Kim, J.; Lee, S. S.; Park, K.-M. Bull. Kor: Chem. Soc. 2007, 28, 873. (e) An, B.-K,; Kwon, S.-K.; Park, S. Y. Bull. Korean Chem. Soc. 2005, 26, 1555.

2. (a) Mattoussi, H.; Murata, H.; Merritt, C. D.; Iizumi, Y.; Kido, J.; Kafafi, Z. H. J. Appl. Phys. 1999, 86, 2642. (b) Choi, K.; Lee, C.; Lee, K. H.; Park, S. J.; Son, S. U.; Chung, Y. K.; Hong, J.-I, Bull. Korean Chem. Soc. 2006, 27, 1549.

3. (a) Tao, S.; Peng, Z,; Zhang, X.; Wang, P.; Lee, C.-S.; Lee, S.-T. Ad, Finct. Mater, 2005, 15, 1716. (b) Lim, S.-J.; An, B.-K.; Jung, S. D.; Chung, M.-A.; Park, S. Y. Angew. Chem. Int. Ed. 2004, 43, 6346. (c) Lee, J. H.; Hwang, D. H. Chem. Contmitm. $2003,2836$.

4. Zeng, Q.; Li, Z.; Dong, Y.; Di, C.; Qin, A.; Hong, Y.; Ji, L.; Zhu, Z.; Jim, C. K. W.; Yu, G.; Li, Q.; Li, Z.; Liu, Y.; Qin, J.; Tang, B. Z. Chem. Commun, 2007, $1,70$.

5. Han, M.; Lee, S.; Jung, J.; Park, K.-M.; Kwon, S.-K.; Ko, J.; Lee, P. H.; Kang. Y. Tetrahedron 2006, 62, 9769.

6. Lakowicz, J. R. Principles of Fhorescence Spcetroscopy; Kluwer Academic: New York, 1996.

7. Williams, A. T. R.; Winfield, S. A.; Miller, J. N. Analyst 1983, 108,1067 .

8. Morison, D. J.; Trefz, T. K.; Piers, W. E.; McDonald, R.; Parvez, M. J. Org. Chem. 2005, 70, 5309.

9. Liu, X.-M.; He, C.; Huang, J.; Xu, J. Chem, Mater: 2005, 17, 434. (references ciled therein)

10. Yamada, S.; Ishii, E.; Konno, T.; Ishihata, T. Org. Biomol. Chem. $2007,5,1442$.

11. Bruker, SANTPLUSNT Version 6.22. Sothware Rejerence Manual Bruker AXS: Madison, Wisconsin, 2000.

12. Bruker, SHELXTL NT Version 6.10. Program for Solttion and Refinement of Crystal Strtictures; Bruker AXS: Madison, Wisconsin, 2000 . 